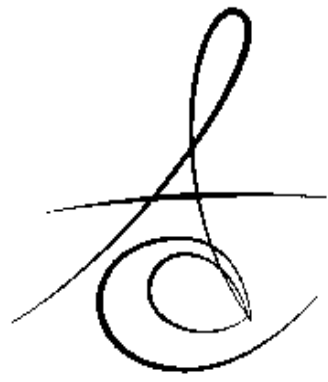

Dr. Öğr. Üyesi Sercan KÜçÜKKURT

\section{SİNİR YARALANMALARI: NEDENLERİ, TEŞHİS VE TEDAVİLERİ}

NERVE INJURIES: CAUSES, DIAGNOSIS AND TREATMENTS

Makale Kodu/Article code: 3158

Makale Gönderilme tarihi: 27.11 .2016

Kabul Tarihi: 14.02.2017

öz

Trigeminal sinir özellikle maksillofasiyal cerrahi girişimler ya da bölgede oluşan travmalar sonucu sıklıkla zarar görebilmektedir. Sinir zedelenme riski taşıyan cerrahi işlemler; gömülü diş çekimleri, fasiyal travmalar ve tedavileri, ortognatik cerrahi, dental implant cerrahisi, baş-boyun bölgesinde bulunan lezyonların tedavisi, preprotetik cerrahi işlemler şeklinde sıralanabilir. Hastanın yaşam kalitesini ciddi oranda düşüren bu istenmeyen durumla başa çıkabilmek için sinir üzerinde oluşan hasar tipleri, nedenleri, teşhisi ve tedavileri konusunda bilgi sahibi olunmalıdır. Bu derlemede sinir hasarları ve bu durumun hem girişimsel hem girişimsel olmayan tedavileri hakkında mevcut kitap bilgileri ile güncel literatür bilgilerini harmanlanarak, bu bölgede çalışan klinisyenlerin bilgi birikiminin arttırılması ve güncellenmesi amaçlanmaktadır.

Anahtar Kelimeler: sinir, sinir yaralanmaları, medikal tedavi, cerrahi tedavi

\author{
Dr. Dt. Murat ÖZLE ${ }^{* * *}$
}

Dr. Öğr. Üyesi Hüseyin Can TÜKEL ${ }^{* *}$

Dr. Dt. Murat ÖZLE 
ise Sdyney Sunderland'in ${ }^{7} 1951^{\prime}$ de axonotmesis ile neurotmesis arasına iki sınıf daha dahil ederek revize ettiği beş aşamalı sınıflandırmadır.

\section{Sunderland Tip 1 (Seddon Neuropraxia)}

Minör gerilim, ödem, hematom ya da lokal enflamasyondaki geçici artış nedeniyle, orta dereceli kompresyonun sinir hücresinde iskemik etki meydana getirmesi sonucu olur. Döner aletlerin oluşturduğu sıcaklığın bölge ısısını $48-54^{\circ} \mathrm{C}$ derece aralığına yükseltmesi tip 1 hasara neden olabilir. Nörolojik etkiler esas olarak uyaranlara cevabın gecikmesine yol açan iletim kesintisidir. İzole olarak nöral demiyelinizasyon oluşsa da Wallerian dejenarasyonu beklenmemektedir. Birkaç günden birkaç haftaya kadar değişen süre içerisinde hızlı, spontan iyileşme beklenmektedir. Baskı yapan yabancı cisim bulunmadığı sürece cerrahi tedavi endikasyonu yoktur ${ }^{8-11}$.

\section{Sunderland Tip 2 (Seddon Axonotmesis)}

Kuvvetli ezilme veya ani gerilme kuvvetleri nedeniyle oluşur ${ }^{12}$. İmplantların veya kırık kemik parçalarının kısmi basısı bu tip zedelenmeleri oluşturabilir. Yapılan duyu testlerinde özellikle hafif dokunmada duyu reflekslerinin kaybolduğu gözlenmektedir. Akson dejenerasyonu olabilse de endonöryum, perinöryum ve epinöryum halen bütünlüklerini korumaktadır. Bu nedenle 2 - 4 ay arasında aksonal rejenerasyon ve duyuların geri kazanımı beklenmektedir. Ekstranöral hematom ve skar formasyonu bu tip zedelenmelerde görülebilmekte ve hafif dereceli nöropatiye yol açabilmektedir. Bu durumlarda cerrahi dekompresyon iyileşmeyi hızlandırabilir ${ }^{8-11}$.

\section{Sunderland Tip 3}

Bu tip yaralanmalar daha ciddi mekanik ezilme, delinme, kimyasal ve termal travmalar sonucu olur. Yara bölgesinde Wallerian dejenerasyonu görülürken, trigeminal gangliyonda hücre kaybına neden olur ${ }^{13}$. Endonöryum hasarlanmış olup intranöral kanama ve skar formasyonu tam akson iyileşmesini engelleyebilir. $\mathrm{Bu}$ nedenle bu tip yaralanmalarda kalıc duyusal bozukluklar görülebilir. Tip 2 ve tip 3 hasarlardan hemen sonra ağrılı yanıcı tarzda parestezi görülebilir. 3 ay içinde duyu testlerine tatmin edici yanıt alınamıyorsa cerrahi olarak bölgenin açılıp, tamir edilmesi uygundur $^{8-11}$.

\section{Sunderland Tip 4}

Çok şiddetli sinir ezilmesi, $55^{\circ} \mathrm{C}$ üzerinde termal etkiler, intranöral lokal anestezik madde enjeksiyonu ve sinire tahriş edici tıbbi ajanların temas etmesi sonrası oluşur. Epinöryum ezilmiş ve devaskülarize olsa da genel olarak bütünlüğünü korur. Sinir içi yapılar hasarlıdır ve yerlerini düzensiz skar dokusu almıştır. Trigeminal gangliyonda hücre nekrozu ve talamik seviye gibi yüksek bölgelerde santral afferent sinir iletim bloğu görülmektedir. Bunun sonucu olarak şiddetli periferal duyu kaybı ve spontan ağrı sendromları gözlenebilir ${ }^{14,}{ }^{15}$. Duyu testlerinde tüm uyaranlara karşı derin hipoestezi ve yara bölgesine perküsyonda hiperpatik ağrı ve parestezi oluşmaktadır. Duyu reflekslerinin tekrardan kazandırılabilmesi için böyle durumlarda oluşmuş olan devamlı nöromanın rezeksiyonu ve sinirin mikrocerrahi ile tamiri gerekmektedir $^{8-11}$.

\section{Sunderland Tip 5 (Seddon Neurotmesis)}

En şiddetli sinir yaralanması tipidir. Sinir gövdesinin tamamen kesildiği, trigeminal sinir hücrelerinde de önemli kayıp olduğu ve amputasyon nöroması oluştuğu gözlenmektedir. Tip 5 hasar gözlenen hastaların çoğu, inatçı ağrı ve yetersiz orofasiyal fonksiyondan şikayetçidir. Cerrahi tedavi bu hastalar için oldukça yararlıdır. Lingual sinirde tip 5 hasar olan neredeyse hiçbir hastada spontan iyileşme görülmez ve hasar doğrulandıktan sonra en kısa sürede mikrocerrahi ile tedavisi yapılmalıdır. Duyu testleri disestezi ile birlikte veya ayrı şekilde anestezi varlığını göstermektedir ${ }^{8-11}$.

\section{HASAR NEDENLERİ}

\section{Fasiyal Travma}

Literatürde fasiyal travmayla ilişkili sinir zedelenmeleri hakkında az sayıda çalışma bulunmaktadır ${ }^{16}$. Bunun nedeni travma hastalarının yaralanmalarının akut fazında duyusal kayıplardan şikayetçi olmamaları ve sonrasında uzun dönem takiplerinin yapılamamasına bağlanabilir. Cerrahlar fraktür tamirine odaklandıkları için, sinir zedelenmelerinin kayıt altına alınması ve duyusal kayıpların tedavisi ikinci plana itilmektedir ${ }^{17}$.

Yapılan çalışmalarda inferior alveolar - mental sinir yaralanmalarının \%76-91 oranında mandibula angulus ve korpus kırıklarında meydana geldiği bildirilmiştir. Tedavi edilen hastaların 1 yıllık takibinde \%32-67'sinde kalıcı duyusal hasar gözlenmiştir ${ }^{18,19}$.

Kalıcı duyusal kaybın esas belirteçleri; fraktür deplasmanının derecesi, yaralanma zamanı ile fraktür tedavisi arası geçen süre ve fraktür onarım tipidir ${ }^{20}$. Yapılan çalışmalara göre, deplase olmayan mandibula fraktürlerinde operasyon öncesi duyusal nöropati

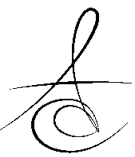


gözlenme oranı \%25 iken, 5mm'den daha fazla deplase fraktürlerde bu oran \%73,5'e çıkmaktadır. Yaralanma zamanı ile operasyon arası geçen süre 1 hafta veya fazla olduğu durumlarda nöropati oluşma riski artmaktadır. Fraktür tamir tipi de nöropati oluşumunda etkili bir faktördür. Mandibula fraktürlerinin açık redüksiyonu sonrası kapalı redüksiyona kıyasla daha yüksek oranda uzun süreli nöropati oluştuğu rapor edilmiştir ${ }^{17-21}$.

\section{Lokal Anestezik Madde Enjeksiyonu}

Lokal anestezi enjeksiyonundan sonra parestezi oluşma sıklığı tam olarak bilinmemektedir. Harn ve ark. $^{22}$ yaptığı çalışmada 9.587 inferior alveolar ve lingual sinir anestezisinde \%3.62 oranında geçici parestezi ve $\% 1.8$ oranında uzun süreli ( $>1$ yıl ) parestezi bildirilmiştir.

Anestezi uygulaması sonrası parestezi oluşması çeşitli teorilerle açıklanmaya çalışılmıştır; iğne ile direk travma, lokal anestezik maddenin toksisitesi, epinöral hematom, iğnenin enjeksiyon sırasında kemiğe teması sonrası ucunun çatallanması ve geri çekilirken sinirin yaralaması bu teorilerden bazılarıdır. Bu durumlardan iğnenin bükülmesi sonrası yaralanma ve lokal anestezik maddenin toksisitesine bağlı paresteziler genellikle uzun süreli olurken, iğne ile direk travma ve epinöral hematom kısa süreli spontan iyileşen paresteziye neden olduğu bildirilmektedir ${ }^{5}$.

Lokal anestezik madde enjeksiyonuna bağlı sinir zedelenmelerinde en sık karşılaşılan semptom dizestezidir. Vakaların çoğunda parestezi 8 hafta içinde kendiliğinden iyileşir. 8 haftadan uzun süreli vakaların sadece üçte biri spontan iyileşme gösterir. Enjeksiyon ilişkili sinir zedelenmelerinde çoğu vaka farmakoterapi ile tedavi edilmeye çalışılır ${ }^{5}$.

\section{Ortognatik Cerrahi}

Ortognatik cerrahi sonrası sinir hasarı sık karşılaşılan bir komplikasyon olup inferior alveolar, lingual, infraorbital ve nadir olarak da maksiller sinir dallarını etkilemektedir ${ }^{23,24}$. Yaralanmalar cerrahi ekipmanla delinme, laserasyonlar, osteotomi sonrası mobilizasyon sırasında gerilme veya rijit fiksasyon amacıyla vida yerleştirilmesi sırasında sinire basıdan kaynaklanabilir. 23, 25, 26

Bilateral sagital split osteotomisi (BSSO) sonrasındaki ilk hafta parestezi görülmesi neredeyse beklenen bir durumdur ${ }^{25}$. Yapılan çalışmalarda inferior alveolar sinir zedelenmesi oranı BSSO sonrasındaki ilk haftada \%97'dir. Cerrahi sonrası inferior alveolar sinir duyu kaybı sıklıkları çalışmacılara göre farlılık göstermektedir. Örneğin işlem tekniği ve chisel kullanımı sinir hasarı oranını artırmaktadır. ${ }^{27}$. Al-Bishri ve ark. ${ }^{28}$ tarafından $\% 11.6$ ve Kallela ve ark. ${ }^{29}$ tarafından \%27 olarak bildirilmiştir. Ortognatik cerrahi sırasında lingual sinirin de zedelenme riski bulunur. Mandibulanın retromolar bölgesinde bikortikal vida fiksasyonu sırasında lingual sinir korunmazsa, vidalar mediyal korteksi delerek lingual sinire zarar verebilir. ${ }^{23,25,} 26$

\section{4. İmplant Cerrahisi}

Mandibulaya uygulanan dental implant cerrahisi inferior alveolar ve mental sinir yaralanmaları açısından önemli bir risk faktörü iken lingual sinir için daha düşük oranda risk içermektedir. Dental implant cerrahisine bağlı yaralanmalar genellikle Sunderland tip 1, 2 ve 3 yaralanmalar olup, travmaya bağlı doku kaybı veya sinirin kesilmesi genellikle görülmemektedir ${ }^{30}$. Mandibulaya dental implant yerleştirilmesi sonrası akut yaralanmaların sıklığı \% 0 - 44 arasında değişmektedir ve ortalama insidansı \% 5 - 15'tir. Kalıc nöropatiler (>1 yıl) $\%$ 0-19 (ortalama $\%$ 8.5) olarak rapor edilmiştir ${ }^{30,31}$.

Dental implant cerrahisine bağlı sinir zedelenmelerinin nedenleri arasında: implant veya döner alet nedeniyle mekanik travma, döner alet kullanımına bağlı indirekt termal travma, kortikal kemiğin mandibular kanalın içine çökmesi sonucu indirek mekanik travma, mandibular kanal içine kanama bulunmaktadır ${ }^{32}$. Özellikle posterior mandibulada implant cerrahisi sonrası sinir zedelenmesinin en önemli nedeni pilot frezin kanalın üst korteksini delmesi ve inferior alveolar veni (daha az sıklıkla arteri) zedelemesidir. Burada oluşan kanama implant yerleştirilmesi sonrası tampone edilmiş olup, kompartman sendromu adı verilen sinir üzerinde artan bir basınç oluşmuna neden olur. Bu tip zedelenmeler uzun süreli disestezi ile sonuçlanmaktadır ${ }^{30,32-34}$.

Akut sinir zedelenmesi oluştuğu ve 40 saatten fazla süren duyusal kayıp gözlendiği vakalarda post operatif görüntüleme yöntemleriyle implant ve mandibular kanal arasındaki anatomik ilişki değerlendirilmelidir. İmplant mandibular kanal içerisindeyse, implantın çıkartılıp yerine daha geniş çaplı, daha kısa bir implant yerleştirilmesiyle damar sinir paketi dekomprese edilir. Hastaya medikal destek olarak 5 gün boyunca kortikosteriod ve ağrı kontrolü için antienflamatuvar analjezikler önerilmelidir ${ }^{32-34}$. 
Sinirin açılıp, dekomprese edilip, tamiri için mikrocerrahi uygulanması endikasyonları; Postoperatif görüntülemede direkt sinir zedelenmesi olduğuna dair objektif bulguların olması, dental implant cerrahisi sonrası bir aydan fazla süren anestezi ya da fonksiyonları engelleyen hipoestezi veya bir aydan fazla süren, medikal tedavi ile geçmeyen disestezidir ${ }^{32,34}$.

\section{Gömülü Üçüncü Molar Cerrahisi}

Gömülü üçüncü molar diş cerrahisine bağlı komplikasyonlar sinir zedelenmesi görülen vakalarının en büyük kısmını ve yaklaşık $\% 60$ 'ını oluşturmakta$\mathrm{dır}^{35}$. Gömülü üçüncü molar diş cerrahisinde sinir zedelenmesi; lokal anestezi enjeksiyonunda, insizyon sırasında, kemik kaldırılması veya dişin bölünmesi sırasında, lingual yumuşak dokular travmatize edilirse, damar sinir paketi ekspoze olmuş vakalarda soket kürete edilirken, çekim bölgesine tetrasiklin içerikli antibiyotik gibi nörotoksik tıbbi ajanların uygulanması nedeniyle ve son olarak dikiş safhasında oluşabiliir ${ }^{1,4,8,10,13}$.

535 oral ve maksillofasiyal cerrahın katıldığı bir araştırmada, 12 aylık sürede hekimlerin \%95.5'nin İAS hasarı ile \%53'nün ise lingual sinir hasarı ile en az bir kere karşılaştı̆ı bildirilmiştir. Toplam sinir yaralanması oranı İAS için yaklaşık her 2500 vakada 1 ve lingual sinir için 10.000 vakada 1 olarak hesaplanmıştır. Üçüncü molar cerrahisine bağlı inferior alveolar sinir zedelenmelerinin görülme sıklığı $\% 0.41$ ile $\% 7.5$ arasında değişmektedir. Lingual sinir hasarı insidansı ise $\% 1-22$ arasındadır ${ }^{1}$.

Gömülü üçüncü molar cerrahisi sonrası sinir zedelenmeleri için pek çok hazırlayıcı faktör bulunmaktadır. Bunlar arasında hasta yaşı, cinsiyet, dişin kemik içindeki derinliği, dişin mesiodistal ve lingual açıları, lingual korteks kalınlığı, köklerin ayrıması, cerrahın tecrübesi bulunmaktadır ${ }^{1}$.

Rood ve Shebab ${ }^{36}$ tarafindan yapılan araştırmada, panoramik radyografi üzerinde inferior alveolar kanal ve diş arasındaki potansiyel komşuluğun belirteçleri 8 kriterde sıralanmışır.

1. Kök ucunda karaltı

2. Kökün yön değiştirmesi

3. Kökün daralması

4. Kökün apeksinde çatallanma

5. Kanalın etrafındaki radyoopak çizgide kesinti

6. Kanalın yönünü değiştirmesi

7. Kanalın daralması

\section{SİNİR DUYU HASARLARININ TEŞHİSİ}

Sinir duyu testlerinin amacl; duyusal zararın ana hatlarıla belirlenmesi, zararın karakteri ile büyüklüğünü ölçmek ve ilerleyen zamanlarda gelişmeleri objektif olarak karşılaştırabilmektir. Sinir hasarları, bölgenin mekanoreseptör (Dokunma basıncı ve noktasını hissetme), termoreseptör (Soğuk-sıcağın ayırt edilmesi), nosiseptör (Ağrı hissetme) gibi duyusal algılamalarından biri ya da birkaçını etkileyebilir. Değişik testler kullanılarak hangi sinir lifinin iyileşme kaydettiği belirlenir. Temel testler ${ }^{10}$;

1. Hafif dokunma: Etkilenen bölgeye pamuk pelet ile dokunarak etkilenen sahanın boyutlarının belirlenmesi

2. İğne (pinprick): Basit bir iğne ya da basınç ölçerli bir iğne yardımıyla etkilenen bölgenin belirlenmesi

3. İki nokta ayrımı: Farklı mesafelerde yerleştirilen iki iğne arasında kalan bölgede hissiz sahanın belirlenmesi

4. Isı değişikliği: Soğuk veya sıcak su emdirilmiş pamuk paletlerle bölgenin ısıyı algılamasının belirlenmesi

5. Yönsel duyu: Pamuk paleti sağdan sola, soldan sağa farklı yönlerde sürerek hastanın yönü hissedip hissetmediğinin belirlenmesi

6. Dokunma noktasını hissetme: Sivri ve künt cisimlerle ayrı ayrı dokunarak cismin künt ya da sivri olmasını hasta tarafindan belirlenmesi.

7. Fotoğraflama: Çeşitli testlerle sınırları belirlenen sahanın kalemler yardımıyla işaretlenmesi ve seanslar arası karşılaştııııması

Duyusal sinir hasarlarında belgelendirme, sorunun niteliğinin ve sinir hasar tipinin sınıflandırılmasında oldukça önemlidir. Anamnez alınırken önemli noktalar; yaralanmanın nedeni, zamanı ve semptomlardaki ilerlemelerdir. Mahon ve ark. ${ }^{10}$ anamnez sırasında sorulması gereken soruları 10 madde de sıralamışlardır:

1. Duyusal bozukluklar ne zaman başladı? (Geç dönemde başlangıç enfeksiyon veya postoperatif fraktür belirtisi olabilir)

2. Belirtileri tarif edebilir misiniz? (Tamamen hissizlik, yanma, ağrı, karıncalanma vb.)

3. Aile bireylerinde kronik postoperatif ağıı geçmişi var mı?

4. Etkilenen bölge bastıııldığında çökme hissi oluşuyor mu?

5. Duyusal bozukluğun karakterinde ilk güne göre

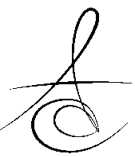


değişiklik var mı? (Anestezi olan bölgenin paresteziye dönmesi his kaybının gerilemesi şeklinde yorumlanabilir.)

6. Değişiklik hissettiğiniz bölgeyi sınırlarını çizebilir misiniz?

7. İlk güne göre his kaybı oluşan bölgenin alanında artma ya da azalma şeklinde bir değişim var mı?

8. Bulguların şiddetinde bir artış ya da azalma mevcut mu?

9. Konuşmada, çiğnemede, yutkunma sırasında dudak bölgenizi ısırma gibi problemler yaşıyor musunuz?

10. Yaşadığınız bu durum günlük hayatınızı, yaşam kalitenizi ne kadar etkiledi.

Duyusal bozuklukların tanımlanmasında bazı terimler ${ }^{37}$

- Aneztesi: Uyaranlara karşı tamamen algı, duyu kaybı

- Hipoestezi: Uyaranlara karşı azalmış duyu (Özel duyular hariç)

- Hiperestezi: Uyaranlara karşı artmış duyu (Özel duyular hariç)

- Parestezi: Spontan veya uyaranlar sonucu oluşan anormal duyu

- Dizestezi: Spontan veya uyaranlar sonucu oluşan rahatsız edici anormal duyu

- Hiperaljezi: Ağrılı bir uyarana karşı normalden şiddetli oluşan duyusal cevap

- Allodini: Normalde ağriya neden olamayan bir uyarana karşı oluşan ağrılı duyusal cevap

MANDİBULAR SİNİR YARALANMALARINA TEDAVİ YAKLAŞIMLARI

1. Cerrahi Olmayan Tedavi Yaklaşımları

1.1. Farmakolojik Tedavi

Periferal sinir zedelenmelerinde farmakolojik tedavi anormal duyu ve dizestezi şikayeti olan hastalar için uygulanmaktadır. Vakaların çoğu için hastayı deneyimli bir nöroloji uzmanı veya fasiyal ağrı uzmanına konsülte etmek uygundur. Yapılan çalışmalarda postoperatif sinir hasarının tedavisi amacıyla birçok farmakolojik ajan kullanılması önerilmiştir ${ }^{38}$ :

Steroid Tedavisi: Bu tedavinin amacı perinöral ödemi azaltıp sinir üzerindeki basıyı kaldırmaktır. Sistemik steroid tedavisinin bu alanda etkinliği hakkında çok az veri olmasına karşın, sinir zedelenmesi sonrası kullanımı hekimin sorunu çözmek için uygulayabileceği basit bir müdahalededir. Seo ve ark. ${ }^{26}$ sagital split osteotomisi uyguladığı ve 4 farklı gruba ayırdığı 27 hastaya farklı sürelerde steroid tedavisi uygulamış ve tedaviden 4 hafta sonra değerlendirilen sonuçlarda steroid kullanımının sinir yaralanmalarının iyileşmesinde anlamlı etkisi olduğunu belirtmişlerdir.

Antioksidanlar: Steroidin antioksidan etkisinin sağlanması ve istenmeyen yan etkilerinden kurtulmak için kullanılmaktadır ${ }^{38,} 39$.

Gangliozidler: Merkezi sinir sisteminde çok sayıda bulunan, sinir rejenerasyonu ve nörit gelişimini hızlandıran ve dejenerasyonu engelleyen glikolipidlerdir. Travmayı takiben 72 saat içinde verilmeleri durumunda daha etkili oldukları ve geç dönemde rejenerasyonu arttırarak iyileşme sürecine katkı sağladıkları bildirilmiştir ${ }^{38,39}$.

Kaspaz İnhibitörleri: Nörolojik hasar oluşmasından sorumlu apoptik hücre ölümünü bloke etmektedir $^{38,39}$.

Kalpain İnhibitörleri: Kalpain onarılamayacak kadar hasar görmüş hücrelerin hücre iskeletinin parçalanmasından sorumludur. Hücre apoptozunun yavaşlatılmasını ve hücre iskeletinin şekillenmesini sağlar ${ }^{38,39}$.

Selektif COX-2 İnhibitörleri: Nöron koruyucu ve klinik iyileşmeyi arttırıcı etkileri vardır ${ }^{38,} 39$.

\subsection{Düşük Seviyeli Lazer Tedavisi}

Düşük seviyeli lazerlerin (Galyum-alüminyumarsenür, dalga boyu $830 \mathrm{~nm}$ ) sinir iyileşmesinde kullanılması umut verici bir uygulamadır. Farmakolojik ve cerrahi tedaviye yanıt vermeyen inatçı vakalarda düşük seviyeli lazer uygulamasının objektif ve subjektif olarak sinir iyileşmesini olumlu etkilediği yapılan bazı çalışmalarda gösterilmiştir ${ }^{4}$. Miloro ve $\operatorname{ark}^{40}$. sagittal split osteotomisi sonrası sinir hasarı oluşan hastalarda uyguladığı düşük seviyeli lazer terapilerinin iyileşmeyi hızlandırarak başarılı sonuçlar verdiğini bildirmiştir. Khullar ve ark. ${ }^{41,42}$ yaptıkları iki çalışmada toplam 31 hastada düşük seviyeli lazer tedavisi ile plasebo uygulanan iki hasta grubunda lazer tedavisinin olumlu etkileri olduğunu rapor etmiştir. Lazer uygulanan gruplarda hastanın uyarana tepki vermesi için uygulanması gereken kuvvetin gram cinsinden daha az olduğunu bildirmiştir. Midamba ve ark. ${ }^{43}$ yaptıkları çalışmada 8 lingual sinir ve 4 inferior alveolar sinir hasarının tedavisi amaciyla düşük seviyeli lazer terapisi uygulamışlardır. Çalışmada hastalara haftada 3 kez olmak üzere 1 ila 8 hafta arasında terapi yapılmıştır. Yapılan 2 yıllık takiplerde lingual sinir hasarı bulunan hastaların

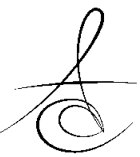


1 'inde tamamen iyileşme, 6'sında ciddi oranda iyileşme ve 1 'inde sınırlı oranda iyileşme rapor edilmiştir. İnerior alveolar sinir hasarı bulunan hastaların ise 1 'inde ciddi oranlarda iyileşme, 2'sinde sınırlı oranda iyileşme ve 1 'inde ise hiçbir değişim olmadığı bildirilmiştir. Araştırmacılar hasar oluşum zamanı ile tedavi süreci arasında geçen zamanın tedaviye etkisi hakkında açık bir yargı belirtmezken, 2 yılı aşan vakalarda bile bir miktar olumlu gelişmeler olabileceğini vurgulamışlardır. Pol ve ark. ${ }^{44}$ tarafından yapılan çalışmada alveolaris inferior sinir yaralanması nedeniyle parestezi şikayeti bulunan 57 hastada düşük seviyeli lazer terapisinin sonuçlarını rapor edilmiştir. Her hastayı, GaAs diyot lazer ile haftada bir kez, $10 \mathrm{doz}$ lazer tedavisine tabi tutmuşlar ve hastaların\% 83.3'ünde önemli nörosensoriyel düzelme olduğunu göstermiştir.

\subsection{Akupunktur}

Sinir hasarlarının tedavisinde akupunktur uygulaması hakkında Ka ve ark. ${ }^{45}$ yaptıkları çalışmada 6 lingual sinir ve 27 inferior alveolar sinirde hipoestezi veya anestezi tipi hasarları tedavi etmek üzere akupunktur uygulamasından yararlanmışlardır. Hastalara akupunktur iğnesi ya da elektrikli akupunktur iğnesi ile maksillofasiyal bölgede ve etkilenen sahada bulunan 7 akupunktur noktasından tedavi yapmışlardır. Şiddetli vakalarda ek olarak moxibustion (akupunktur iğnesinin ısıtılarak uygulanması) uygulaması yapılmıştır. Çalışmanın 6 aylık döneminin ardından lingual sinir hasarı bulunan hastaların 2'sinde tamamen iyileşme, 1'inde ciddi oranda iyileşme, 3 'inde sınırlı oranda iyileşme rapor edilmiştir. İnferior alveolar sinir hasarı bulunan hastalarda ise 4 tanesinde tamamen iyileşme, 8 'inde ciddi oranda iyileşme, 10'unda sınırlı oranda iyileşme rapor edilirken, 1'inde ise hiçbir gelişme gözlenmediği rapor edilmemiştir.

\section{Cerrahi Tedaviler}

\subsection{Cerrahi zamanlaması}

Cerrahi işlemler yaralanma zamanı ve cerrahi işlem arasında geçen süreye göre; primer (hemen), gecikmiş primer ve sekonder olmak üzere üçe ayrılır. Primer tedavi ameliyat esnasında sinirin açığa çıktığı ve yaralanmanın hemen 0 anda görüldüğü vakalarda uygulanır. Eğer mümkünse primer cerrahi biyolojik olarak en uygun tedavi yöntemidir. Aksonal rejenerasyon en hızlı yaralanma sonrası ilk 3 haftada olmaktadır ve bu süre zarfında nöroma veya skar formasyonu henüz oluşmamıştır. 4, 35, 46

\subsection{Mikrocerrahi Teknikleri}

Aşırı posterior ve inferiora konumlanmış İAS zedelenmesi harici yaralanmalar ağız içinden yaklaşımla tedavi edilebilmektedir. Sinir tamirlerindeki tedavi basamakları ${ }^{47}$ :

1. Yabancı cisimlerin çıkarılması ve sinire bası yapan çevre dokuların rahatlatılmasını içeren dekompresyon,

2. Yara bölgesinin saptanması, tanımlanması ve travmatik nöromanın eksizyonu,

3. Mikrosüturlarla nörorafi (direk reanastomoz),

4. Büyük sinir dokusu kaybolduğu durumlarda greft kullanımını kapsar.

\subsubsection{Dekompresyon}

Eksternal nöroliz olarak da bilinen dekompresyon tekniği, sinir tamir prosedürünün ilk safhasıdır. Travma sonucu bölgede oluşan yaralanma, siniri sıkıştıran veya baskı yapan skar dokusu oluşumuna sebep olabilir. Oluşan baskı ve sıkışma sonucu sinirsel iletimde zayıflama oluşabilir. Bazı vakalarda bu skar dokusu sinirin iyileşme sürecini de olumsuz etkileyebilir. Bu teknik yaralanma bölgesinde sinirin, sinir dalını çevreleyen bağ dokusundan ayrılması ve bölgede oluşan fibrotik veya skar dokularının temizlenmesini içerir $^{37}$. Epinöral damarlanmaya zarar verilmeden uygulanır. Sunderland tip 1 ve 2 vakalarda yüksek büyütme ile sinir detaylı biçimde incelenir. Eğer nöroma varlığına rastlanmaz ise dekompresyon tedavi için yeterlidir ${ }^{47}$.

\subsubsection{Nöroma rezeksiyonu}

Dekompresyon sonrası hareketli olan sinir, yara bölgesinin proksimal ve distal uçlarından sabitlenir. Sinir üzerinde amputasyon veya devamlı nöroma varlığı incelenir. Nöroma varlığında sinir yüksek büyütmeyle incelenerek lezyonun boyutları saptanır. Saptanan lezyon $3 \mathrm{~mm}$. sağlam dokuyu da içerek şekilde eksize ederek histopatolojik incelemeye gönderilir. Yeterli eksizyon sonrası intakt fasiküllerin epinöral sinir uçlarında herni yaptığı gözlenir. Eksizyonun yeterliliğinden şüphe duyuluyorsa, $1 \mathrm{~mm}$.'lik biyopsi örnekleri ile frozen-section biyopsi uygulanabilir. Çok nadir de olsa distal sinir ucunun kaybolması gibi sinir tamirinin mümkün olmadığı durumlarda, proksimal sinir gövdesi iskelet kası gibi komşu, canlı dokulara dikilir ${ }^{47-49}$.

\subsubsection{Internal nöroliz}

Daha sıklıkla geniş spinal sinirlerde nöroma varlığında uygulanan bir metot olup trigeminal sinir hasarında uygulanmasına şüpheyle yaklaşılmaktadır.

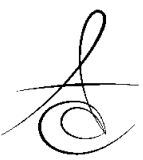


İşlem sırasında yaralanan bölgedeki epinöryum tabakasının içine serum fizyolojik solüsyonu enjekte edilir. Enjeksiyon sonrası balon gibi şişen bölgeye uzunlamasına insizyon yapılıp, sinirin içyapıları ekspoze edilir. Efektif olarak uygulandığında bu yöntem internal sinir fibrozisi serbestleştirir ve sinir fasiküllerini rahatlatır. İnternal nöroliz endikasyonları esas olarak hafif dereceli internal fibrozisi bulunan Sunderland tip 2 ve 3 vakalardır. Eğer işlem sonrası rahatlama olmaz ve internal fibrozis hala duruyorsa bölge rezeke edilip anastomoz yapılır 4 9, 35, 37, 47, 49, 50 .

\subsubsection{Nörorafi}

$\mathrm{Bu}$ yöntem literatürde coaptation ve direk anastamoz olarak da geçmektedir. Teknik sinir dalında bir kopma mevcutsa ve iki parça birbirine gerilimsiz olarak dikilebilecek durumdaysa uygulanabilir. Genellikle $1 \mathrm{~cm}$ 'in altındaki uzunluklarda sinirler gerilimsiz olarak dikilebilirler. Nöroma rezeksiyonu sonrası direk epinöral mikrocerrahi anastamoz ile uygulanabilir. Sinir reaktif olmayan süturlar kullanılarak 4 veya 6 yerinden dairesel olarak dikilir. Nörorafi sonrası sütur bölgelerinde şişme veya buruşma olmamalı ve sinir bırakıldığında pasif olarak uzanmalıdır. Çalışmalar $25 \mathrm{~g}$. ve üzeri gerilme kuvvetlerinde aksonal büyümenin engellendiğini göstermiştir. Bu nedenle minimal gerilme kuvveti önemlidir ${ }^{47}$.

\subsubsection{Sinir greftleri}

Nörorafinin sinirde gerilme oluşturmadan uygulanmasının mümkün olmadığı durumlarda sinir greftleri uygulanır. En sık kullanılan otojen sinir greftleri sural sinir, medial antebrakial kutanöz sinir ve posterior auricular sinirdir. Sural sinirin seçilme nedeni çap ve fasikül sayısı açısından trigeminal sinire benzemesidir. Ayrıca oldukça uzun boyutlarda greft alınabilmesi ve hastanın dönor bölge hasarını kolay tolere edebilmesi sural sinirin avantajları arasındadır. Posterior auricular sinir greft kullanımının avantajı ise ekstraoral cerrahi işlem yapılacağı zaman aynı insizyonla greftin de alınması dönor bölge komplikasyonlarını azaltmaktadır. Medial antebrakial kutanöz sinirden 10 $\mathrm{cm}$, lateral antebrakial kutanöz sinirden $20 \mathrm{~cm}$ 'ye kadar sinir grefti elde edilebilmektedir. Diğer yönden sinir hasarlarının onarımında kullanılabilen allogreftlerde piyasada mevcuttur ${ }^{49,51-53}$. Zuniga ve ark ${ }^{3}$. Yaptıkları çalışmada sinir allogreftlerinden yararlanarak 26 hastaların mandibular sinir dallarına uyguladıkları rekonstrüksiyon sonrası herhangi bir yan etki oluşmadan hastaların $\% 87$ sinde olumlu gelişmeler gözlediklerini rapor etmiştir. Ayrıca ilk 90 günlük dönemde sinir hasarı onarımının daha başarılı sonuçlar verdiği de aynı çalışmada vurgulanmıştır. Miloro ve ark. ${ }^{51}$ lingual sinirin greftler yardımıyla onarımının uzun dönemde daha başarılı sonuçlar verdiğini belirtmiştir.

\subsubsection{Entübasyon teknikleri}

Sinir rejenerasyonu için dönor bölge morbiditesini ortadan kaldırmak amacıyla entübasyon teknikleri geliştirilmiştir. Bu teknikte kullanılan tüpler otojen olabildiği gibi alloplastik materyalden de olabilir. Otojen seçenekler arasında ven, kollajen ve kas greftleri bulunur ${ }^{54,55}$. Ven greftleri sıklıkla posterior fasiyal ven veya external juguler venden alınmaktadır. Jones ve ark. ${ }^{46}$ tarafından İAS hasarı olan 5 hastaya posterior fasiyal venden alınan parça ile greft uygulaması yapılmıştır. Hastalardan 4'ü sorunsuz iyileşirken 1'inde iyileşme kaydedilememiştir. Alloplastik materyaller ise poliglikolik asit, polimerik silikon ve genişleyen politetrafloroetilenden yapılmıştır.

\section{SONUÇ}

Birçok kaynak ve çalışmada belirtildiği gibi sinir hasarlarının tedavisinde zamanında ve erken müdahale oldukça önemli bir rol oynamaktadır. Sinir yaralanmaları meydana geldiği zaman önemli olan; yaralanmanın sebebi, derecesi ve uygulanabilecek tedavileri hızlı bir şekilde değerlendirmek, etkeni ortadan kaldırmak, gerekli tedavilere bir an önce başlamak ya da tedavinin yapılabileceği bir merkeze yönlendirmektir. Yalnızca medikal tedavi ile başa çıkılabilecek bir hasarı cerrahi olarak tedavi etmeye çalışmak ya da cerrahi tedavi gerektiren bir durumu müdahale etmeden zamana bırakmak telafisi mümkün olmayan hasarlara sebep olabilir.

Sercan Küçükkurt: ORCID ID: 0000-0002-4095-957X

Can Tükel: $O R C I D I D: 0000-0002-6723-0842$

Murat Özle: ORCID ID: 0000-0002-3710-5127

\section{KAYNAKLAR}

1. Robert RC, Bacchetti P, Pogrel MA. Frequency of trigeminal nerve injuries following third molar removal. J Oral Maxillofac Surg 2005;63:732-5; discussion 6.

2. Pogrel MA, Kaban LB. Injuries to the inferior alveolar and lingual nerves. J Calif Dent Assoc $1993 ; 21: 50-4$. 
3. Zuniga JR. Sensory outcomes after reconstruction of lingual and inferior alveolar nerve discontinuities using processed nerve allograft--a case series. J Oral Maxillofac Surg 2015;73:734-44.

4. Leung YY, Fung PP, Cheung LK. Treatment modalities of neurosensory deficit after lower third molar surgery: a systematic review. J Oral Maxillofac Surg 2012;70:768-78.

5. Smith $\mathrm{MH}$, Lung KE. Nerve injuries after dental injection: a review of the literature. J Can Dent Assoc 2006; 72:559-64.

6. Seddon HJ. Three types of nerve injury. Brain 1943;66.

7. Sunderland S. A classification of peripheral nerve injuries producing loss of function. Brain 1951;74:491-516.

8. Auyong TG, Le A. Dentoalveolar nerve injury. Oral Maxillofac Surg Clin North Am 2011;23:395400.

9. Miloro M, Ghali G, Larsen P, Waite P. Peterson's Principles of Oral and Maxillofacial Surgery 3rd ed: PMPH USA; 2011. 1664 p.

10. Mahon N, Stassen LF. Post-extraction inferior alveolar nerve neurosensory disturbances--a guide to their evaluation and practical management. J Ir Dent Assoc. 2014;60:241-50.

11. Meshram VS, Meshram PV, Lambade P. Assessment of nerve injuries after surgical removal of mandibular third molar: A prospective study. Asian J Neurosc 2013; 2013(291926).

12. Terzis J, Faibisoff $B$, Williams $B$. The nerve gap: suture under tension vs. graft. Plast Reconstr Surg 1975;56:166-70.

13. Eriksson L, Hillerup S, Reibel J, Persson S, Brun A. Traumatic changes of the inferior alveolar nerve and Gasserian ganglion after removal of a mandibular third molar: report of a case. J Oral Maxillofac Surg 2006;64:1821-5.

14. Dubner $\mathrm{R}$, Ren K. Brainstem mechanisms of persistent pain following injury. J Orofac Pain 2004;18:299-305.

15. Sessle BJ, Yao D, Nishiura H, Yoshino K, Lee JC, Martin RE, et al. Properties and plasticity of the primate somatosensory and motor cortex related to orofacial sensorimotor function. Clin Exp Pharmacol Physiol 2005;32:109-14.
16. Thurmuller P, Dodson T, Kaban L. Nerve injuries associated with facial trauma: Natural history, management, and outcomes of repair. Oral Maxillofac Surg Clin North Am 2001;283(13).

17. Schultze-Mosgau S, Erbe M, Rudolph D, Ott R, Neukam FW. Prospective study on post-traumatic and postoperative sensory disturbances of the inferior alveolar nerve and infraorbital nerve in mandibular and midfacial fractures. J Craniomaxillofac Surg 1999;27:86-93.

18. Iizuka $T$, Lindqvist $C$. Sensory disturbances associated with rigid internal fixation of mandibular fractures. J Oral Maxillofac Surg 1991;49:1264-8.

19. Marchena JM, Padwa BL, Kaban LB. Sensory abnormalities associated with mandibular fractures: incidence and natural history. J Oral Maxillofac Surg 1998;56:822-5; discussion 5-6.

20. Tay AB, Lai JB, Lye KW, Wong WY, Nadkarni NV, $\mathrm{Li} W$, et al. Inferior Alveolar nerve injury in trauma-induced mandible fractures. J Oral Maxillofac Surg 2015;73:1328-40.

21. Schenkel JS, Jacobsen C, Rostetter C, Gratz KW, Rucker M, Gander T. Inferior alveolar nerve function after open reduction and internal fixation of mandibular fractures. J Craniomaxillofac Surg 2016;44:743-8.

22. Harn SD, Durham TM. Incidence of lingual nerve trauma and postinjection complications in conventional mandibular block anesthesia. J Am Dent Assoc 1990;121:519-23.

23. Panula K, Finne K, Oikarinen K. Incidence of complications and problems related to orthognathic surgery: a review of 655 patients. J Oral Maxillofac Surg 2001;59:1128-36; discussion 37.

24. Westermark $A$, Bystedt $H$, von Konow L. Inferior alveolar nerve function after sagittal split osteotomy of the mandible: correlation with degree of intraoperative nerve encounter and other variables in 496 operations. $\mathrm{Br} \mathrm{J}$ Oral Maxillofac Surg 1998;36:429-33.

25. Politis C, Lambrichts I, Agbaje JO. Neuropathic pain after orthognathic surgery. Oral Surg Oral Med Oral Pathol Oral Radiol 2014;117:e102-7. 
26. Seo K, Tanaka Y, Terumitsu M, Someya G. Efficacy of steroid treatment for sensory impairment after orthognathic surgery. J Oral Maxillofac Surg 2004;62:1193-7.

27. Mensink G, Gooris PJ, Bergsma JE, van Hooft E, van Merkesteyn JP. Influence of BSSO surgical technique on postoperative inferior alveolar nerve hypoesthesia: a systematic review of the literature. J Craniomaxillofac Surg 2014;42:97682.

28. Al-Bishri A, Rosenquist J, Sunzel B. On neurosensory disturbance after sagittal split osteotomy. J Oral Maxillofac Surg 2004;62:14726.

29. Kallela I, Laine P, Suuronen R, Lindqvist C, Iizuka $\mathrm{T}$. Assessment of material- and technique-related complications following sagittal split osteotomies stabilized by biodegradable polylactide screws. Oral Surg Oral Med Oral Pathol Oral Radiol Endod 2005;99:4-10.

30. Bartling R, Freeman K, Kraut RA. The incidence of altered sensation of the mental nerve after mandibular implant placement. J Oral Maxillofac Surg 1999;57:1408-12.

31. Hirsch JM, Branemark PI. Fixture stability and nerve function after transposition and lateralization of the inferior alveolar nerve and fixture installation. $\mathrm{Br} \mathrm{J}$ Oral Maxillofac Surg 1995;33:276-81.

32. Greenstein G, Carpentieri JR, Cavallaro J. Nerve damage related to implant dentistry: incidence, diagnosis, and management. Compend Contin Educ Dent 2015;36:652-9; quiz 60.

33. Steinberg MJ, Kelly PD. Implant-related nerve injuries. Dent Clin North Am 2015;59:357-73.

34. Du Toit J, Gluckman H, Gamil R, Renton T. Implant Injury Case Series and Review of the Literature Part 1: Inferior Alveolar Nerve Injury. J Oral Implantol 2015;41:e144-51.

35. Jones RH. Repair of the trigeminal nerve: a review. Aust Dent J 2010;55:112-9.

36. Rood JP, Shehab BA. The radiological prediction of inferior alveolar nerve injury during third molar surgery. $\mathrm{Br} \mathrm{J}$ Oral Maxillofac Surg 1990;28:20-5.
37. Coulthard P, Kushnerev E, Yates JM, Walsh T, Patel N, Bailey $E$, et al. Interventions for iatrogenic inferior alveolar and lingual nerve injury. Cochrane Database Syst Rev 2014; 4: CD005293.

38. Uygun S, Apaydın A. Maksillofasiyal bölgede periferik sinir yaralanmaları ve tedavisi. İstanbul Üniv Diş Fak Derg 2008;42:11-7.

39. Palaoğlu S, Akbay A, Bozkurt G. Akut omurilik yaralanmasının tedavisinde iyileşmeyi hızlandıran farmakolojik ve cerrahi girişimler. Türkiye Fiziksel Tıp ve Rehabilitasyon Derg 2002;48:3-11.

40. Miloro M, Repasky M. Low-level laser effect on neurosensory recovery after sagittal ramus osteotomy. Oral Surg Oral Med Oral Pathol Oral Radiol Endod 2000;89:12-8.

41. Khullar SM, Brodin P, Barkvoll P, Haanaes HR. Preliminary study of low-level laser for treatment of long-standing sensory aberrations in the inferior alveolar nerve. J Oral Maxillofac Surg 1996;54:2-7; discussion -8.

42. Khullar SM, Emami B, Westermark A, Haanaes HR. Effect of low-level laser treatment on neurosensory deficits subsequent to sagittal split ramus osteotomy. Oral Surg Oral Med Oral Pathol Oral Radiol Endod 1996;82:132-8.

43. Midamba ED, Haanaes HR. Effect of low level laser therapy (LLLT) on inferior alveolar, mental and lingual nerves after traumatic injury in 16 patients. A pilot study. Laser Theraphy 1993;5:89.

44. Pol R, Gallesio G, Riso M, Ruggiero T, Scarano A, Mortellaro C, Mozzati M. Effects of superpulsed, low-level laser therapy on neurosensory recovery of the inferior alveolar nerve. J Craniofac Surg 2016;27:1215-9.

45. Ka L, Hirata $Y$, Kobayashi A, Wake H, Kino K, Amagasa $\mathrm{T}$. Treatment results of acupuncture in inferior alveolar and lingual nerves sensory paralysis after oral surgery. Kokubyo Gakkai Zasshi 2006;73:40-6.

46. Jones RH. The use of vein grafts in the repair of the inferior alveolar nerve following surgery. Aust Dent J 2010;55:207-13. 
47. Meyer RA, Bagheri SC. Microsurgical reconstruction of the trigeminal nerve. Oral Maxillofac Surg Clin North Am 2013;25:287-302.

48. Dellon $\mathrm{AL}$, Mackinnon $\mathrm{SE}$, Pestronk $\mathrm{A}$. Implantation of sensory nerve into muscle: preliminary clinical and experimental observations on neuroma formation. Ann Plast Surg 1984;12:30-40.

49. Biglioli F, Allevi F, Lozza A. Surgical treatment of painful lesions of the inferior alveolar nerve. J Craniomaxillofac Surg 2015;43:1541-5.

50. Meyer RA, Bagheri SC. Nerve Gap Reconstruction. J Oral Maxillofac Surg 2015; 73: 1885.

51. Miloro M, Ruckman P, 3rd, Kolokythas A. Lingual nerve repair: to graft or not to graft? J Oral Maxillofac Surg 2015;73:1844-50.

52. Wolford LM, Rodrigues DB. Autogenous grafts/allografts/conduits for bridging peripheral trigeminal nerve gaps. Atlas of the Oral Maxillofac Surg Clin North Am 2011;19:91-107.

53. Er N, Çapar GD, Çanakci G, Alkan A. Peripheral nerve injury and treatment in dentistry. J Dent Fac Atatürk Uni 2016;1:147-52.

54. Pogrel MA, Maghen A. The use of autogenous vein grafts for inferior alveolar and lingual nerve reconstruction. J Oral Maxillofac Surg 2001; 59: 985-8; discussion 8-93.

55. Eppley BL, Delfino JJ. Collagen tube repair of the mandibular nerve: a preliminary investigation in the rat. J Oral Maxillofac Surg 1988;46:41-7.

\author{
Yazışma Adresi \\ Sercan KÜÇÜKKURT \\ Aydın Üniversitesi \\ Diş Hekimliği Fakültesi \\ Ağız, Diş ve Çene Cerrahisi ABD, \\ ISTANBUL - TÜRKİYE \\ 05326205590 \\ e-mail: skucukkurt@gmail.com
}

